\title{
COMPARATIVE. PATHOLOGY
}

AND

\section{THERAPEUTICS.}

Vol. XXI.NO. 4. DECEMBER 3I, I908.

MEASURES TAKEN AGAINST ANIMAL TUBERCULOSIS IN DENMARK ${ }^{1}$

By Dr BERnARD BANG, Professor of Pathology and Therapeutics, Royal Veterinary School, Copenhagen, Delegate of the Danish Government.

(Report of the Danish National Committee submitted to the International Congress on Tuberculosis, Washington, D.C., I908.)

MEASURes against tuberculosis among domestic animals were first taken by the State by the Act of 14 th April 1893 relating to the Prevention of Infectious Diseases among Domestic Animals. According to section II of this Act cattle owners are prohibited:-

(a) From sending animals (cattle and pigs) obviously suffering from tuberculosis to fairs and cattle shows, to common pastures, stables, etc., of other cattle owners, as well as from selling such animals, except for slaughter.

(b) From selling or using as human food animals or any part of an animal obviously suffering from tuberculosis, unless a veterinary surgeon's certificate be produced stating that a previous examination of the carcase and the entrails has shown the meat to be fit for human consumption.

(c) From selling the milk of cows suffering from tuberculosis of the udder, or using it as human food or in the preparation of food or as food for animals, except when boiled.

These measures have, however, produced few practical results. It is true that a number of animals have been rejected when presented

I Reprinterl from the "American Veterinary Review," November 1908. 
for admittance at fairs and common pastures or for exportation, and no doubt the sale of such animals for other than killing purposes has now and then been prevented; still, it is difficult to impose fines in such cases, the term "obviously tuberculous" being too vague. Paragraphs $b$ and $c$ were amended later, so as to provide more fully for the cases mentioned in them.

By the Act of I4th April 1893 relating to State Help towards the Combating of Tuberculosis among Cattle an attempt was made to encourage cattle farmers to take measures to get rid of tuberculosis among their stock. By this Act a sum of $50,000 \mathrm{Kr} .{ }^{1}$ yearly (afterwards increased to $100,000 \mathrm{Kr}$.) was, for a term of five years, placed at the disposal of the Ministry of Agriculture to pay for gratis distribution of tuberculin, for the injection of this substance by veterinary surgeons, for measuring the temperature of the animals, and for giving directions as to isolation, if the farmer in question wished to apply the tuberculin test to ascertain which of his animals were infected with tuberculosis, but only on condition of his binding himself to keep the healthy animals safely isolated from those suffering from tuberculosis.

As the primary object of these measures was to promote the breeding of healthy young cattle, at first only young animals were tested gratis ; soon, however, the test was also applied gratis in the case of full-grown animals, and gradually it became quite common to subject the whole stock of a farm to the tuberculin test in order to make it possible to isolate the healthy among the full-grown animals.

The passing of this Act was chiefly due to a proposal of B. Bang, who for some years past had been studying the efficacy of tuberculin for proving the existence of tuberculosis among cattle and other domestic animals, and who had worked out a system for the extermination of tuberculosis in an infected stock by thorough isolation of the animals that were not yet attacked, and by preventing the transmission of infection through raw milk.

According to Bang, tuberculosis is a purely contagious disease. It is true that infection may take place in the uterus, so that the calf is born tuberculous, but this happens very rarely-practically only when the cow is highly tuberculous. Most calves are born healthy, even if born of somewhat tuberculous cows, and they will remain so if they are only preserved from infection. In the first place, tubercle bacilli are not ubiquitous. They are mostly found in stables where tuberculous animals discharging tubercle bacilli are or have lately been stabled. Secondly, raw milk very often transmits infection, mostly, it is true, when the udder of the cow is attacked, but also frequently when this is not the case, partly because tubercle bacilli may be excreted through an apparently healthy udder if the cow is highly tuberculous, partly because the pure milk may be fouled by the introduction of tubercle bacilli through flux of the uterus or by particles of the fæces of highly tuberculous cows.

The tuberculin tests proved that a great number of cattle of all the herds among which tuberculosis had long been prevalent were infected with this disease. Post-mortem examinations proved, however, that most of the reacting animals were only slightly affected; in many cases only small caseous-calcareous deposits were found in a

$11 \mathrm{Kr}$. (Krone) =about 13 pence. 
few of the lymphatic glands-processes that no doubt often remain unchanged for years or are even sometimes cured.

According to Bang, therefore, there was no reason to kill milch cows that did not show clinical signs of tuberculosis, but only reaction to tuberculin. So long as they were stabled in isolated stables there was no reason why they should be killed or why their milk should not be used and calves bred from them, provided the latter were as soon as possible removed from the infected stable, and were not in.fected by being fed on the raw milk of tuberculous animals. The highly tuberculous animals should not of course be allowed to form part of the stock, but should be killed as soon as possible-a measure which had certainly been taken rather often in former times, though not nearly as often as circumstances demanded.

It will be seen that these measures-devised by Bang and founded on the above facts-for combating tuberculosis among cattle interfered as little as possible with the breeding. He wanted farmers to remove from their stock only such animals as, from reasons of general economy, they would feel inclined to remove, i.e., the animals that a merely clinical examination proved to be tuberculous. They were allowed to keep those that did not appear tuberculous until subjected to the tuberculin test, as long as they found they yielded sufficient milk, and to breed their calves, if only they took good care to keep the latter isolated from the perfectly healthy animals. If the isolation could not be carried out in any safer way (which would, of course, be preferable), a part of the stable might be partitioned off by a wooden partition, reaching from the ceiling to the floor. The common water-pipe would have to be cut off, or, if this was not practicable, it might be sufficient to let the water pass first through the part of the stable reserved for the healthy animals. If absolutely necessary, it would be permissible to have tight-fitting doors in the partition wall, though this has certainly often proved a drawback, it being, of course, very difficult to keep such doors shut when not in actual use. Whenever it is at all possible, as it would be in the case of a large stock, there ought to be two sets of stable hands-one for the healthy animals, one for the infected ones. If this was not possible, the servants would have to tend and milk the healthy animals first, and have two sets of boots or shoes and overalls, as well as of implements, one for each class of animal. In the pastures the two divisions would also have to be kept apart as much as possible, though the danger is considered to be less when the animals are grazing than when they are in the stable.

As from the very outset it was quite clear to Bang that isolation of the animals on the same farm, especially if such had to be effected in one building by means of a partition wall, could not be a complete guarantee against the introduction of contagious matter among the hegalthy animals, and that the tuberculin test was not in every case quite infallible (for instance, the animals might have been infected just before the test, and so be unable to react), he directed that the healthy division was to be subjected to the tuberculin test once, or preferably twice, a year, so that those animals, which in spite of the isolation proved to be infected, might be removed without delay from the healthy division to the reacting one, his object being the gradual purification of an infected stock during the course of several years. 
It would thus become possible for a farmer possessing a stock in itself valuable, though infected with tuberculosis, to gradually convert it into a healthy one by breeding from his own stock.

As early as 1892 Bang was enabled, by a special Government grant, to demonstrate the practicability of his theories by gradually changing a highly tuberculous stock into a healthy one. The farm of Thurebylille was selected for this experiment. On the first application of the test I 3 I animals reacted, while only seventy-seven, mostly young animals, were found to be healthy. Of the milch cows 80 per cent. reacted, and of the young cattle and calves only 40 per cent. The isolation of the two classes, the reacting and the healthy ones, from each other was effected by partitioning off a part of the stable with a solid wooden partition, the shed occupied by the calves forming part of the healthy division. There were two sets of stable hands, one for each of the two divisions, which were, moreover, kept apart when grazing as well as in the stable.

The practicability of the plan was soon proved, as the calves which were born in the infected division of reacting parents were nearly all found to be healthy (very few being born tuberculous) and remained so, provided they were at once removed from the infected stable and fed on boiled milk, their mother's milk (raw) only being given to them on the first day.

Still, as had been expected, year by year some of the animals of the healthy division did not pass the half-yearly test; in other words, some infection was introduced into the healthy division in spite of the isolation. Generally it was only I or a few per cent. that did not pass the test; on a few occasions, however, it was as much as 9 per cent. It will thus be seen that the elimination of the infection proceeded rather slowly, but then circumstances were rather unfavourable, because the isolation was not a thorough one, the daily control less effective than might have been desired, and, lastly, because the farmer was not sufficiently alive to the importance of removing highly tuberculous animals, discharging great quantities of bacilli, from the reacting division.

In spite of these drawbacks the healthy division increased year by year, and at last the task of eliminating the disease was successfully accomplished by selling the remainder of the reacting division, about thirty head of cattle. The farm is now one of those that supply Copenhagen with "Milk for Infants" (i.e., superior milk). The stock is every year subjected to the tuberculin test, and the last time, in 1907, not one out of 2 I I animals reacted.

As the Act of 1893 provided generous assistance to such cattle farmers as were anxious to improve the sanitary condition of their stock by employing the method which had been tried at Thurebylille, a great number of both small and large farmers set to work, in many cases with excellent results. At all large farms, however, where tuberculosis is generally very prevalent, the elimination of infection progressed slowly, just as had been the case at Thurebylille, a few of the animals of the healthy division reacting whenever they were subjected to the test a second time. The stricter the isolation the better the results; the best results being, of course, achieved when it was possible to remove the healthy animals to another farm. The thorough disinfection of stables where highly tuberculous animals 
had been stabled, in order to destroy all contagious matter, often proved a very difficult task, especially in buildings where the woodwork and the. stone floors were old and dilapidated. Where tuberculosis was not very prevalent, as was very often the case among small herds, and sometimes even among large ones (in one case, for instance, only six animals out of 134 reacted), it was of course easy enough to root out the infection completely.

By means of the numerous tuberculin tests which-especially during the first few years after the introduction of Bang's method-were applied to cattle in all parts of Denmark much valuable information was obtained as to the extent of tuberculosis in Denmark, closely corresponding with the results obtained in all other countries where tuberculin was largely used. In many herds the disease was very prevalent. Among large herds (i.e., herds numbering fifty or more animals) only few proved to be quite free from tuberculosis. Among stocks of this size the average number of reacting animals was 50 or 60 per cent.; while among small herds (numbering less than fifty animals) a great number, about one-fourth, were perfectly healthy, and the number of reacting animals in infected "small" stocks was considerably less than that of the large ones-hardly 30 per cent.

The fact that a great many small stocks consist of none but healthy animals (in 1898 there were 2203 stocks, numbering 30, IOI animalson an average fourteen in each) clearly shows that the opinion, prevalent among many medical men, that tubercle bacilli are ubiquitous is fallacious. They are never found except in places where animals (or human beings) discharging tubercle bacilli live or have lately lived. Tuberculosis is a purely contagious disease.

This view is strikingly confirmed by a closer examination of herds among which tuberculosis is found. Only such herds are perfectly healthy as are kept up by breeding, receiving hardly any increase from outside except a calf now and then, while the prevalence of tuberculosis is generally the greater the more frequently the stock is increased by buying cattle at fairs, and consequently the most infected parts of the country are those where a brisk trade in cattle is being done, and where buying and selling of cattle is common.

Another way by which infection may be introduced among hitherto healthy stocks is by feeding calves on skimmed milk from a cooperative dairy, amongst whose suppliers will always be found owners of tuberculous cattle. In cases where the infection had been introduced through the milk the cows were very often healthy, while it was the calves or the young cattle that reacted; sometimes the peculiar fact might be observed that only animals of the same agefor instance, yearlings or two-year-olds-reacted, and when this happened the heating apparatus of the dairy was found to have been out of order just at the time when milk was supplied to the set of animals that had reacted.

In all other cases the tuberculin test proved conclusively that tuberculosis is more prevalent among old than among young cattle. A close examination of 40,624 head of cattle, which during the years I898-1904 were subjected to the tuberculin test for the first time, showed that of calves under six months I 2.1 per cent. reacted, of yearlings (from six to eighteen months) 27.5 per cent., of two-yearolds (from one-and-a-half to two-and-a-half) 38.6 per cent., of full- 
grown animals (from two-and-a-half to five) $44^{\circ} 9$ per cent., and of animals over five years old 48 per cent.-figures which correspond with the results of tuberculin tests in other countries, as well as with the experiences of slaughter-houses and with the results of the study. of human tuberculosis.

The method recommended by Bang for enabling cattle farmers to combat tuberculosis by their own efforts, i.e., strict isolation of the healthy animals and feeding calves on uninfected milk [milk of perfectly healthy animals or milk heated to $85^{\circ} \mathrm{C}$. (now only $80^{\circ} \mathrm{C}$.)], had at first many enthusiastic followers, as will be seen by the following tables :-

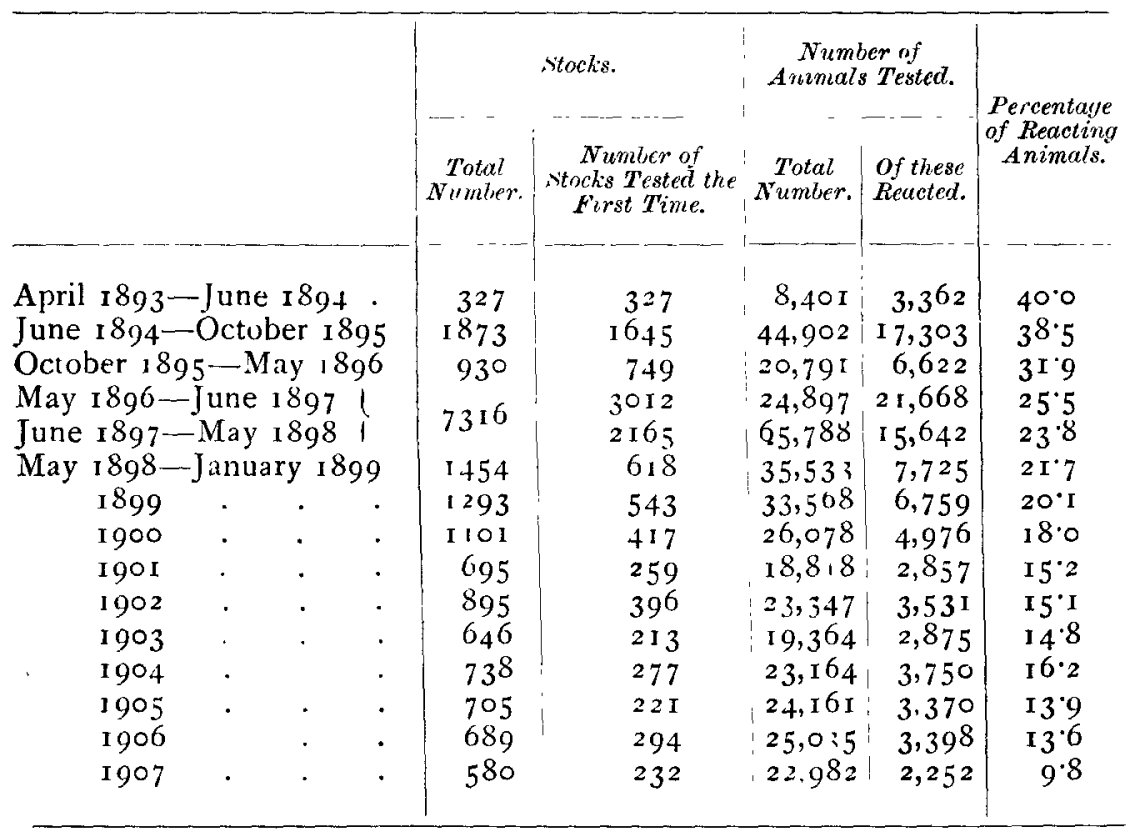

After a few years, however, there was a sad falling off. The carrying out of the above measures demands great vigilance and perseverance on the part of farmers as well as on that of their servants, qualities not often met with. The importance of strict isolation was not at first realised by all; the watchfulness was often relaxed, the disinfection of the stables was not always as thorough as it should have been, the milk was not always sufficiently heated. Many farmers thought the method too troublesome in the long run. If accidents happened, so that too many animals of the healthy division reacted on the repetition of the test, the farmer would lose courage and listen to the many voices (especially those of butchers and cattle dealers), eager to assure him that the tuberculin test was mere humbug. The serious misuse of tuberculin in employing it for the immunisation of cattle intended for export to Germany for killing purposes-these animals, according to the peculiar German regulations, are to be subjected to the tuberculin test in passing quarantine at the German frontier-contributed greatly to the 
dissemination of wrong ideas among the public. The well-known and unfortunate circumstance that highly tuberculous and consequently infectious animals sometimes do not react at all, or only very slightly, must also be taken into account, veterinary surgeons sometimes neglecting to subject the non-reacting animals to a sufficiently careful clinical examination, so that it sometimes happened that a specially infectious animal was placed among the healthy ones.

However, although there was a great falling off, many farmers have persevered, and most of them, both owners of large and of small stocks, have obtained excellent results. For instance, on the first application of the test in 1894 at the farm of Borupgaard in Jutland, 139 out of the total number ( 82 per cent. of the full-grown animals) reacted, and only 86 were found to be healthy. When the test was applied at the same farm in 1908 , out of 245 animals only I calf reacted, and so slightly that the reaction must be considered doubtful. This excellent result had been attained by strict isolation (division of the large stable by a wooden partition and separate stables for calves and young cattle). According to the careful calculations of the owner of the farm, the total expense of the isolation was about $1000 \mathrm{Kr}$.

When the test was first applied in 1896 at Count Wedell's estate, Wedellsborg (Funen), I 66 of the animals reacted, and only 74 were found to be healthy. Now there is a stock of 264 head of cattle, of which only 3 reacted in 1908 . In this case the division of the stable had been effected by means of a brick wall. Although during the first few years very few of the animals did not pass the half-yearly tests, the result was now and then rather bad, as when on one occasion as many as 22 per cent. reacted, which discouraged the owner of the estate so much that he very nearly gave up the whole thing. Fortunately, however, he persevered, and eventually reaped the reward of his exertions.

A well-known cattle-breeder, Mr Ahlmann of Langholt and Striben (Jutland), had, in $1895,27 \mathrm{I}$ reacting and 68 healthy animals. At present the reacting division has been reduced to 10 , while of the remaining stock on his two farms only 6 out of 373 animals reacted at the last test. Mr E. Tutein of Edelgave (Sealand) had, in I 895, I 5 reacting animals and 48 healthy ones; the last time the test was applied only 2 out of 158 reacted. As early as $1899 \mathrm{Bang}$, in the report submitted by him to the Veterinary Congress of Baden-Baden (Congress Report, Vol. I., p. 54I), expressed his opinion that the best way of rooting out tuberculosis in a large stock among which the disease had long been prevalent would be to subject at first only calves and young cattle and none of the full-grown animals to the test, as experience had shown that among such a stock 80 per cent. or more of the full-grown animals would react. Consequently only very little would be gained by isolating the Io or 20 per cent. of non-reacting cows, as a great number of these animals, having for a long time been exposed to infection, would turn out to be infected even if they did not react. Not a few of such cows will be found to have in some of the lymphatic glands small tubercles of long standing, encysted, it is true, and consequently harmless, but still in some cases liable to break out again. By not subjecting the full- 
grown animals of their stock to the test farmers would avoid the unpleasantness of learning (and of having to tell their friends) that the greater part of their stock was infected, and the task of isolation would be the easier at first.

It is really beyond comprehension that every great cattle farmer, who is the owner of a valuable herd and knows it to be infected, does not take the simple precaution of isolating his calves from the full-grown animals of his stock and feeding them on uninfected milk, i.e., milk that is sufficiently heated or milk from a few perfectly healthy (non-reacting and clinically examined) cows. In countries where the "artificial" feeding which is common in Denmark is unknown, a way out of the difficulty would be to make some perfectly healthy cows act as wet nurses and suckle the calves. Indeed, as has been proved by the Hungarian Ujhelyi, good results may be achieved even if the mothers are allowed to nourish their own calves, provided the calves are kept in separate stables except when they are let in to their mothers for feeding two or three times a day. This breaking away from the isolation rule involves, of course, some danger of infection; there is, however, a great difference between such a brief exposure to infection and constant cohabitation in the same stable day and night.

Of course the isolated calves should be subjected to half-yearly tuberculin tests so that the infected ones may be removed as soon as possible, and the healthy stock which is being formed by the above measures should of course be kept continually apart from the old infected stock. The Ostertag method of keeping the healthy animals isolated only as long as they are young and later stabling them together with the full-grown cattle cannot by any means be recommended, as the infected stock, even though its sanitary condition may be improved by removing the most infectious animals by means of a careful clinical control, will never be so completely rid of animals that may transmit infection as to obviate further danger. This cannot be attained by the clinical control alone.

For large landed proprietors, owners of several farms, it will be an easy matter to get rid of tuberculosis by sending all the healthy animals of their stock to one of their farms and gradually, by means of the above method, eliminating the infection from the herds of their other farms. The following account of how matters were managed at the farm of Ourupgaard and three other farms at Falster belonging to Mr Fr. Tesdorpf may serve as an instance to show how infection may be rooted out in this easy and cheap way. Here a beginning was made in 1893 by subjecting calves and young cattle of the stock of Ourupgaard, but no full-grown animals, to the tuberculin test, with the result that 3 I reacted while I 52 were found to be healthy. The healthy animals were strictly isolated, first at Ourupgaard in separate stables, later at two of the other farms. During the succeeding years the testing of this healthy stock of young animals, as also of the calves that were born, was continued. At first the result here, as at many other farms, was sometimes rather unsatisfactory, for instance, in 1896 , when 23 animals out of 361 reacted, but in time, as the isolation was carried out more and more carefully, better results were obtained, until last year, when at the four farms belonging to $\mathrm{Mr}$ Tesdorpf, only I I animals out of 876 
reacted. At one of the farms there is still a herd of II 4 reacting (or non-tested) animals.

Just as good results have been obtained by Count DanneskjoldSamsoe at his three large farms in the island of Samso. Here, as early as in I89 $\mathrm{I}$, a beginning was made by testing the calves, of which relatively few reacted. The reacting animals were killed, and the healthy calves and young cattle were kept isolated for some time, only, however, until the beginning of the calving season, which was certainly a great mistake (one that could not be prevented, the test being a private one). They were then placed in the large, wellappointed stable together with the non-tested cows, which, though apparently healthy, infected the others, so that when at length Bang, in I898, prevailed upon Count Danneskjold-Samsoe to have the whole stock, which during six or seven years had been continually recruited with absolutely healthy young animals, subjected to the test, 286 animals reacted, while only 29 were found to be healthy. From that time the healthy animals were kept isolated at two of the other farms. In I9OI there were at one of these farms 208 animals, which all passed the test, and at another 126,4 of which reacted. In December 1907 there were in the healthy division 593 animals, of which 2 reacted, though doubtfully, on being subjected to the test. In addition, there was still at one of the farms a reacting division of about thirty cows. So the great task of changing a large tuberculous stock into an all but healthy one by breeding had been accomplished in ten years, an excellent result indeed.

Excellent results may also be obtained by isolation at one farm, as will be seen by the two following instances. In 1896 Farmer Langermann of Faurholm had forty-five calves subjected to the test, fifteen of which reacted. From that time until now the calves bred at the farm have been tested and kept isolated, while the full-grown animals of the stock were not tested at first. That they were highly tuberculous was proved by the fact that nineteen of the apparently healthiest cows reacted on their being subjected in I 900 to the test as an experiment. Gradually a perfectly healthy stock has been bred, numbering, in April 1908, I97 animals, none of which reacted when tested.

At the large estate of Voergaard in Jutland (belonging to $\mathrm{Mr}$ Scavenius) the same method of leaving the full-grown animals untested at first was adopted. In I 895 ninety-four yearlings and twoyear-olds were tested, half of which reacted. The result of continued isolation of the calves and the young cattle and repeated tuberculin tests (of the calves twice yearly, of the older animals only once) is that there were in 1907 healthy divisions numbering 443 animals, of which only nine reacted upon the application of the test, and a reacting division of forty-one animals. The manager of the cattle farm was much struck by the gratifying fact that the cows live much longer now than at the time when tuberculosis was prevalent among them, a fact that is of course of the greatest importance as regards the profits of cattle farming, and which is generally taken too little into account.

It is by no means only at the large farms that excellent results have been obtained by the method of isolation. It is indeed quite possible to carry it out at the same farms as well. The difficulty at 
these farms is, of course, to find two sets of stable hands to tend and milk the two divisions, but, on the other hand, there is the advantage that at a small farm nothing escapes notice, and that the farmer can personally see to the execution of his orders. A small farmer, if he has only intelligence enough to grasp the main point, can much more easily than a great landowner take care that the transmission of infection is avoided. Generally it will not be necessary to have two sets of stable hands, if only the rule of tending and milking the healthy division first is strictly adhered to, and if the hands change their boots or shoes, and, preferably, their overalls as well, on going from one division to another, and use different sets of implements in the two divisions.

It is a fact that the carrying out of the method of isolation has been attended with excellent results on many small farms. Where only few animals reacted it was easy enough to get rid of the disease, but also in cases where almost the whole stock was infected the gradual elimination was often successfully accomplished. It may here be mentioned that it repays one's trouble to work for small farmers, men who have felt their economic existence threatened by the prevalence of tuberculosis among their cattle. These men are deeply impressed with the importance of getting rid of the disease, and so take more care in performing their daily duties to avoid the transmission of infection than do most others.

The result of a computation made by Bang in 1905 was that at sixty-six small farms, of which the average number of stock was twenty-nine head of cattle, a gradual changing of what were for the most part highly tuberculous herds into healthy ones had been successfully accomplished by the method of isolation. When this work was begun the total number of reacting animals on these sixtysix farms was I045, and of healthy ones 780 ; when it was finished there were 1896 healthy animals and none reacting. On being asked, several of these farmers told Mr Bang that the work had certainly caused a good deal of trouble, but that the expense was nothing to speak of. Thus one farmer had, by spending a sum of less than $200 \mathrm{Kr}$. on the establishment of two small provisional byres on one of his farms, succeeded in changing his highly tuberculous stock (twelve cows and heifers of which he had to sell for a mere song within a few years) into a perfectly healthy one, numbering thirty head of cattle-in 1907 there were thirty-six-which have been several times subjected to the tuberculin test and have each time been found to be healthy. Other farmers have achieved similar excellent results at still smaller cost.

It will thus be seen that there is not the slighest doubt that both small and large cattle farmers may gradually change a tuberculous stock into a healthy one if they are determined to do it, and if they have quite grasped the nature and the modes of infection of tuberculosis.

N. O. Nielsen, veterinary surgeon (Remkolde, near Vordingborg, Sealand), has had the good idea to persuade a great number of the small cattle farmers of his district to join an association with the object of "promoting the breeding and maintenance of healthy, non-tuberculous stocks of cattle and pigs." Only such farmers are allowed to join who have had their stocks subjected to the tuberculin tests, and, in 
case of its proving only partially healthy, have suitably isolated the healthy animals from the diseased ones. No increase of the stock by animals of other stock except calves under one month is allowed, unless they come from a healthy stock and have been found healthy on being injected with tuberculin. The object of the association is, besides setting a good example, to facilitate the purchase of healthy animals, as members who want to buy or sell may apply for advice to one amongst them, who keeps a list of the farms where healthy animals are for sale. To some of the members is delegated the task of superintending the heating of milk at the dairies. Members pay a subscription of $2 \mathrm{Kr}$. yearly.

The association was started in December 1905, and has prospered so much that it has now 125 members possessing stock amounting to 2740 cows and young cattle. [According to a report, dated Ist January I908, 2070 of the 2442 animals of the association were healthy, and only fourteen of the members had reacting (isolated) animals-372 in all.] Within three years the task of reoting out tuberculosis from twenty-five stocks of cattle has been accomplished by means of killing or selling the reacting animals. (On the first application of the test, eighty-five stocks - most of them very small, it is true-were found to be healthy.) More than half of the cattle of the four parishes, the scene of the labours of the association, belongs to members. There is no doubt that such association may do much towards rousing an interest in small farmers in the great problem: How to breed healthy cattle and pigs. "Union is strength" may be more truly said of Denmark, where so much is achieved by co-operative farming, than of any other country.

The growing interest in the rational application of the tuberculin test and the method of isolation has, in addition to the founding of the above association, manifested itself lately in another way.

During the last seven or eight years several thousand head of Jersey cattle have been imported into Denmark direct from the island of Jersey. These cattle, as well as all other cattle that are imported for breeding purposes, must undergo a brief quarantine detention, and are subjected to the tuberculin test (in accordance with the Act of 5 th February 1904 relating to the Combating of Tuberculosis among Cattle and Pigs). This has further corroborated the truth of the already well-known fact, that tuberculosis is all but unknown among the Jersey cattle, an interesting circumstance which is accounted for by the fact that the Jersey stock has been kept pure for more than 100 years, the importing of cattle, except for immediate slaughter, being prohibited, probably to prevent the introduction of rinderpest. Of the Jersey cattle imported into Denmark only very few animals reacted on being subjected to the test, and when these animals were killed, it was either quite impossible to demonstrate the presence of tuberculosis (accidental fever) or it was found to be present in a very slight degree only (perhaps caused through human infection). On being placed among infected Danish cattle healthy Jersey cows will very soon become tuberculous; sometimes even they have been known to give way to the disease quicker than Danish cattle. The man who first imported Jersey cattle, and who is the most eager advocate of the introduction of this excellent breed, which, owing to its wonderfully rich milk, is of special value to a 
butter-producing country, viz., Mr J. Larsen (Gaardbogaard), was fortunately also a very eager advocate of the use of tuberculin, and has always taken good care to keep his stock free from tuberculosis. Consequently it has been easy for him to induce the majority of the cattle farmers who import Jersey cattle to keep their newly imported animals free from the disease by means of isolation. There are at present about 5000 head of Jersey cattle in Denmark, on small as well as on large farms, most of which are either quite free from tuberculosis or successful efforts are being made to make them so. At many of these farms the stock is composed exclusively of Jersey cattle, at some the breed is mixed.

The foregoing is chiefly an account of what is being done in Denmark to combat tuberculosis among cattle by the cattle farmers assisted by the State, which pays the expenses attendant on the tuberculin tests on condition the farmers bind themselves to keep the healthy animals safely isolated from the infected ones. In conclusion follows an account of the two measures with the same object (as passed by the Legislature):-

The amendment in 1898 of the Tuberculosis Act of 1893 provides that all cows found suffering from tuberculosis of the udder are to be killed, and that a partial compensation is to be paid to the owner by the State: further, that all skimmed milk and buttermilk returned from dairies to be used as food for calves and pigs is previously to be heated to $85^{\circ} \mathrm{C}$. In 1904 an amendment was added providing that the compensation for a cow killed on account of tuberculosis of the udder is to be increased a little, so as to represent one-third the market value of the carcase, calculated at the current average price for meat of inferior quality, if the meat is declared by a veterinary surgeon to be fit for human consumption (which happens very rarely), and five-sixths of the market value of the carcase if the meat is condemned. By an amendment of the provisions relating to the heating of the milk it was provided that the milk is now to be heated to $80^{\circ} \mathrm{C}$. instead of to $85^{\circ} \mathrm{C}$., and that this provision is also to apply to cream destined for the making of butter for exportation. The object of this later provision, which has, of course, in itself nothing to do with the endeavours to combat the prevalence of tuberculosis among domestic animals in Denmark, is to keep Danish butter free from viable tubercle bacilli. It cannot be said to have revolutionised the dairy work to any great extent, as the heating of buttermilk has always been performed indirectly by heating the cream. Long before I 898 it was common enough to heat the cream very considerably, in order to insure the perfect purity of the butter. There is no doubt that the usual heating of the cream and the adding of cultures of acidifying bacteria before the churning has contributed much to the practically invariably superior quality of Danish butter. .

The object of the killing of cows suffering from tuberculosis of the udder is to get rid as soon as possible of these animals, through which, more than through any others, infection may be spread to calves, pigs, and other domestic animals, and also, undoubtedly, to human beings, especially children, if the milk is taken raw. The endeavours to combat tuberculosis of the udder have met with great sympathy among Danish farmers. About 2500 samples of milk of cows suspected of suffering from this form of tuberculosis are sent in 
yearly through veterinary surgeons to the laboratory of $\mathrm{Dr}$ Bang, and the microscopic examination of these samples, either of the particles produced by exudation or, in case of the milk being unchanged, of the sediment after centrifugation, showed tubercle bacilli to be present in about 30 per cent. of the cases. After the killing of the cow parts of the diseased udder are subjected to examination, in order to ascertain the correctness of the diagnosis, which in only about I per cent. of the cases has turned out to be at fault. About 700 cows are killed every year, and the compensation paid for them generally amounts to $50,000 \mathrm{Kr}$. yearly.

The object of the killing of cows suffering from tuberculosis of the udder is of course best attained if the case is established when still at an early stage. The fact is therefore worth mentioning that of the 6228 cows suffering from tuberculosis of the udder destroyed in Denmark in the course of ten years, 2149 , or 345 per cent., were still at a very early stage of the disease, as the secretion of the diseased gland still had the appearance of natural or almost natural milk. In many other cases also the rooting out of these infectious animals has had great hygienic importance, as cows suffering from tuberculosis of the udder may often go on living for months after their milk has changed, and even though at this stage the milk is not generally mixed with uninfected milk it still contributes to spread infection in the stable by being milked on the floor.

The compulsory slaughter of these animals is therefore indubitably justified, but much more ought to be done. The best thing would be to order all cows suffering from "open tuberculosis," i.e., all which discharge tubercle bacilli through any of the excretory ducts, to be destroyed by the owner and partial compensation granted. Should the authorities hesitate for the present from acting upon this recommendation-partly because of the expense, partly because it may be rather difficult in some cases to decide whether a coughing cow is suffering from pulmonary tuberculosis, especially of an ulcerative, infectious form-there is, at any rate, one form of tuberculosis which is extremely easy to diagnose, as the presence of the bacilli may be proved directly, viz., tuberculosis of the uterus. This disease, which seems to be even more frequent than tuberculosis of the udder, is most infectious; not only are enormous masses of tubercle bacilli every day spread in the stable through the discharge from the vagina, but a great number are no doubt mixed with the milk during the milking. It is six years since the veterinary authorities of Denmark recommended that the same action should be taken with regard to cows suffering from this disease as with cows suffering from tuberculosis of the udder, but up to the present day their advice has been disregarded.

The most important of all the measures against tuberculosis among cattle and pigs which have been carried out in Denmark is the law relating to the heating of skimmed milk and buttermilk to $80^{\circ} \mathrm{C}$. before it is returned from the dairies. As in Denmark nearly all milk not sold directly for consumption is sent to co-operative dairies, it is clear that there is very great danger of a wide dissemination of tuberculosis if raw skimmed milk and buttermilk are returned to the suppliers to be used as food for calves and pigs. There will always among suppliers of a dairy be one or more farmers who have a 
highly tuberculous stock, one or more cows of which yield in the course of the year great quantities of infected milk, and so, by employing this milk after it has been skimmed to feed other stocks, the infection is spread to hitherto healthy herds. As mentioned above, this was formerly done on a large scale, and there is no doubt that most stocks of cattle and pigs in Denmark would gradually be infected in this way if measures had not been taken to prevent it. Of course the heating of the whey ought to have been enforced by law as well. This was proposed, but the proposal was not accepted, chiefly because the heating of the whey is rather troublesome. It is, however, to be hoped that this measure will be carried out some day, though, as whey is mostly used for feeding pigs, it is not so important as the other dairy products as regards bovine tuberculosis, and, besides, cheese-making is not nearly so considerable in Denmark as butter-making.

In Denmark the observance of the law regulating the heating of skimmed milk is controlled by the police as well as by the margarine and butter inspectors, who procure samples at the dairies and send them to the laboratory of Prof. Storch, where they are subjected to his colour test, which consists in pouring a few drops of paraphenylendiamin and peroxide of hydrogen into the milk. The milk turns blue if it has not been heated to $80^{\circ} \mathrm{C}$. Offenders against the Act are fined. On the whole the regulations governing the heating of milk are fairly scrupulously carried out, though, of course, there are exceptions. The best plan would be for one or two of the suppliers of each dairy to apply the above easy and simple test every day. This is done in some places, and has produced very good results.

One useful provision of the Tuberculosis Act is that the sediment deposited on the sides of the cream separator is to be burned, which is no doubt always done now. In old days this product was now and then used as food for pigs, and thus many pigs were infected, as it contains enormous masses of tubercle bacilli, which are separated from the milk by the centrifugal force.

\section{ACT OF 5TH FEBRUARY I904, CONTAINING MEASURES AGAINST TUBERCULOSIS AMONG CATTLE AND PIGS.}

A sum of $100,000 \mathrm{Kr}$., granted every year by the Rigsdag (Parliament) on the recommendation of the Committee of Ways and Means, shall be placed at the disposal of the Minister of Agriculture for the support of cattle farmers who wish to employ tuberculin as a diagnostic remedy in combating tuberculosis among their cattle, the tuberculin test being applied according to detailed regulations issued by the Minister. The support shall be granted to none but such farmers as guarantee their ability to keep the animals, proved by the test to be healthy, safely isolated from the animals affected with tuberculosis or which have not been subjected to the tuberculin test.

"The Minister of Agriculture shall, on the same conditions, be entitled to employ part of the sum to support cattle breeding associations which wish to subject the animals selected for breeding purposes to the tuberculin test, as well as to support farmers' associations desiring to subject cows belonging to cottagers to the tuberculin test."

Farmers who do not fulfil their obligations with regard to isolation 
shall return to the State the grants which have been made to them in accordance with the above provisions.

Any veterinary surgeon superintending the application of the tuberculin test on a farm shall satisfy himself, under penalty of a fine, that safe isolation between the animals is established, and if his orders to this effect are not obeyed by the farmer he shall notify this to the chief veterinary surgeon of the country.

"Applications from cattle farmers, cattle-breeding associations, and farmers' associations desiring to take advantage of the opportunity offered to them by this Act of having their cattle subjected to the tuberculin test, shall be sent direct to the Minister of Agriculture."

\section{Section 2.}

Importation of live cattle from abroad shall only take place at such places as are mentioned in the regulations issued by the Minister of Agriculture. Immediately after their arrival the animals shall be quarantined, and shall, in accordance with the regulations of the veterinary police, be subjected to the tuberculin test, according to regulations issued by the Minister of Agriculture, within five days after their arrival at the quarantine stable. After the test the nonreacting animals shall be left at the disposal of the owner, while the reacting animals shall either be returned or taken direct to a public slaughter-house or to a slaughter-house recognised by the Minister of Agriculture, where the same shall be destroyed under control of the veterinary police.

The expenses incurred in providing the requisite quarantine stables at the places of import, as well as the expenses of the tuberculin test, but none of the expenses attendant on the other measures mentioned in this section, shall be borne by the State.

"The regulations relating to tuberculin tests, mentioned in section I, shall also apply to such other diagnostic remedies as may be recommended by veterinary authorities for the combating of tuberculosis among cattle and are approved by the Minister of Agriculture."

\section{Section 3 .}

Animals imported for killing purposes may be exempted from quarantining and the tuberculin tests ordered in section 2.

"Such animals shall, after having been branded (see section 4), be taken direct to a public slaughter-house or to a slaughter-house recognised by the Minister of Agriculture.

"The Minister of Agriculture shall be entitled to permit cattle imported for killing purposes, after having been marked, to be taken direct to a cattle market, where the animals shall be stabled, so as to be, in the opinion of the veterinary police, duly isolated from all other cattle. From this place they shall be taken direct to a public slaughter-house or to a slaughter-house recognised by the Minister of Agriculture."

The animals imported for killing purposes mentioned in this section shall be killed within ten days after their arrival in this country.

\section{Section 4.}

"The Minister of Agriculture shall issue regulations for the marking of the imported animals." 


\section{Section 5 .}

Cows suffering from tuberculosis of the udder shall be killed in accordance with the regulations of the State under control of the veterinary police or in a public slaughter-house. The owner shall be entitled to a compensation for the animal amounting to one-third of the market value of the carcase, calculated at the current price, according to regulations issued by the Minister of Agriculture. The owner shall, further, be entitled to a compensation for such parts of the animal as are declared by the veterinary surgeon to be unfit for human consumption, amounting to half of the value of the condemned meat, calculated as above. Such parts of the animal as are declared fit for human consumption shall be left at the disposal of the owner.

The compensation, as well as the expenses attendant on the killing, shall be paid by the State.

\section{Section 6.}

None but such milk and buttermilk as has been heated to a temperature of at least $64^{\circ}$ Reamur $\left(80^{\circ} \mathrm{C}\right.$.) shall be returned from dairies to serve as food for cattle and pigs. Exceptions from this rule may take place when the heating cannot be performed on account of an accident, which fact shall be made known to the person to whom the milk is to be returned.

The heating mentioned in this section shall also apply to all cream destined for the making of butter for exportation.

The sediment scraped off the sides of the cream separator during the cleaning of the same shall be burned.

\section{Section 7.}

"None but such milk and buttermilk as has been sufficiently proved, in the opinion of the Minister of Agriculture, to have been heated to a temperature of at least $64^{\circ}$ Reamur $\left(80^{\circ} \mathrm{C}\right.$.) shall be imported from abroad. The Minister of Agriculture shall, however, be entitled to grant exemption from the above prohibition when special circumstances necessitate it."

\section{Section 8 .}

The carrying out of the provisions of this Act shall be enforced by the veterinary police, the custom-house officers, and the butter and margarine inspectors in accordance with the directions of the Minister of Agriculture.

\section{Section 9 .}

Offenders against the provisions of sections $1,2,3,6$, and 7 shall be liable to fines of from Io to $20 \mathrm{Kr}$. for the first offence; in case of repetition to fines of from 20 to $200 \mathrm{Kr}$. Repeated offences against section 6 shall not be looked upon as such if at least one year has elapsed since the offender was last fined. The fines shall accrue to the exchequer. The proceedings in these cases shall be summary. In the case mentioned in section 7 the prohibited articles shall be confiscated and heated to the temperature defined in the above section. In Copenhagen the proceeds of the sale of such articles 
shall accrue to the municipal fund; in other places to the poor fund.

\title{
Section Io.
}

This Act, which shall not apply to the Faroe Islands, shall come into force Ist October 1904.

\section{THE RELATION OF HUMAN AND BOVINE TUBERCULOSIS ${ }^{1}$}

\author{
By Professor Robert KoCH.
}

THE question whether or not human and bovine tuberculosis are identical is indeed of high theoretical interest. But the practical importance of the question which concerns the prevention of tuberculosis is of far greater importance. For this reason I will confine myself solely to a consideration of the practical side of the subject.

To Theobald Smith, of Harvard, belongs the credit to have been the first to call attention to certain differences between the tubercle bacilli found in man and in cattle. It was his work which induced me to take up this same study. In co-operation with Schiitz I have undertaken a series of experiments for which we selected cattle, these animals being specially suited for such work.

The results of these experiments have led me to conclusions which I have first communicated to the British Congress on Tuberculosis in I90I. They are in substance as follows :-

(I) The tubercle bacilli of human tuberculosis are different from those of bovine tuberculosis.

(2) Human beings may be infected by bovine tubercle bacilli, but serious diseases from this cause occur very rarely.

(3) Preventive measures against tuberculosis should therefore be directed primarily against the propagation of human tubercle bacilli.

I did not expect that my personal views on the relation of human and bovine tuberculosis would be accepted as final, but I have asked that the experiments of Schuitz and myself be repeated. This has been done since by a host of investigators.

Many sources of error must be considered in research on tuberculosis, and only work in which these errors have been definitely excluded can be accepted as conclusive.

My personal estimate of the value of the work of other authors depends, therefore, on how far these errors have been eliminated. For this reason I will now summarise briefly the requisites for conclusive work on the differentiation between human and bovine tuberculosis.

(I ${ }^{2}$ ) The animals used for experimentation must be entirely free from spontaneous tuberculosis. Since the earliest stages of tuberculous infection cannot be recognised with certainty, errors arising therefrom can only be avoided by experimenting on long series

\footnotetext{
1 Read at the Joint Session of Sections I. and VII. of the International Congress on Tuberculosis in Washington, D. C. September 30, 1908. Reprinted from "Tuberculosis," Vol. VII., p. 491.

This numeration, not contained in the original English text, has been introduced by Koch at the revision for the sake of greater clearness. 